\title{
Alteration of the irisin-brain-derived neurotrophic factor axis contributes to disturbance of mood in COPD patients
}

This article was published in the following Dove Press journal: International Journal of COPD

7 July 2017

Number of times this article has been viewed

\author{
Csaba Papp' \\ Krisztian Pak ${ }^{2}$ \\ Tamas Erdei ${ }^{2}$ \\ Bela Juhasz ${ }^{2}$ \\ Ildiko Seres ${ }^{3}$ \\ Anita Szentpéteri ${ }^{3}$ \\ Laszlo Kardos ${ }^{4}$ \\ Maria Szilasi ${ }^{5}$ \\ Rudolf Gesztelyi² \\ Judit Zsuga' \\ 'Department of Health Systems \\ Management and Quality Management \\ for Health Care, Faculty of Public \\ Health, ${ }^{2}$ Department of Pharmacology \\ and Pharmacotherapy, Faculty of \\ Medicine, ${ }^{3}$ Department of Internal \\ Medicine, Faculty of Medicine, \\ University of Debrecen, ${ }^{4}$ Department \\ of Clinical Pharmacology, Infectious \\ Diseases and Allergology, Kenezy \\ Gyula Teaching County Hospital and \\ Outpatient Clinic, ${ }^{5}$ Department of \\ Pulmonology, Faculty of Medicine, \\ University of Debrecen, Debrecen, \\ Hungary
}

Correspondence: Judit Zsuga Department of Health Systems Management and Quality Management for Health Care, Faculty of Public Health, University of Debrecen, Nagyerdei krt 98, 4032 Debrecen, Hungary

$\mathrm{Tel}+36306250144$

Fax +36 52411717 ext 55187

Email zsuga.judit@med.unideb.hu
Abstract: COPD is accompanied by limited physical activity, worse quality of life, and increased prevalence of depression. A possible link between COPD and depression may be irisin, a myokine, expression of which in the skeletal muscle and brain positively correlates with physical activity. Irisin enhances the synthesis of brain-derived neurotrophic factor (BDNF), a neurotrophin involved in reward-related processes. Thus, we hypothesized that mood disturbances accompanying COPD are reflected by the changes in the irisin-BDNF axis. Case history, routine laboratory parameters, serum irisin and BDNF levels, pulmonary function, and disease-specific quality of life, measured by St George's Respiratory Questionnaire (SGRQ), were determined in a cohort of COPD patients $(n=74)$. Simple and then multiple linear regression were used to evaluate the data. We found that mood disturbances are associated with lower serum irisin levels (SGRQ's Impacts score and reciprocal of irisin showed a strong positive association; $\beta$ : 419.97; 95\% confidence interval $[\mathrm{CI}]: 204.31,635.63 ; P<0.001)$. This association was even stronger among patients in the lower $50 \%$ of BDNF levels ( $\beta$ : 434.11; $95 \%$ CI: $166.17,702.05 ; P=0.002$ ), while it became weaker for patients in the higher $50 \%$ of BDNF concentrations ( $\beta$ : $373.49 ; 95 \%$ CI: $-74.91,821.88 ; P=0.1)$. These results suggest that irisin exerts beneficial effect on mood in COPD patients, possibly by inducing the expression of BDNF in brain areas associated with reward-related processes involved in by depression. Future interventional studies targeting the irisin-BDNF axis (eg, endurance training) are needed to further support this notion.

Keywords: irisin, BDNF, SGRQ, whole-body plethysmography

\section{Introduction}

COPD, by profoundly impacting the patient's quality of life, poses great socio-economic burden for individual patients, their families, and society. ${ }^{1,2}$ COPD primarily worsens quality of life by developing chronic, progressive dyspnea and consequent limitation of physical activity. ${ }^{3}$ Moreover, co-existing mental health problems show higher prevalence in COPD patients than in the general population, ${ }^{2,4}$ with depression and anxiety being present in $\sim 20 \%-40 \%$ and $30 \%-50 \%$ of COPD cases, respectively. ${ }^{2,4-7}$ Disturbance of mood not only causes disability per se but also changes the course of the disease by altering how patients experience and manage their disease, thus worsening their functional and health status. ${ }^{4,8}$ Therefore, the quest to elucidate the potential mechanisms underlying mood disturbances in COPD is ever so pressing.

Irisin is a recently identified putative contraction-regulated myokine that is formed by proteolytic cleavage of transmembrane fibronectin type III domain-containing protein 5 (FNDC5). ${ }^{9}$ Expression of FNDC5 was shown to positively correlate with physical activity in several organs (eg, skeletal muscle and brain) as its increased or 
decreased expression was observed in response to sustained physical training or sedentary lifestyle, respectively. ${ }^{10-12}$ It is interesting that FNDC5 expression has been shown in the ventral tegmental area (VTA) and hippocampus, ${ }^{13}$ structures serving model-free and model-based rewardrelated reinforcement learning processes. ${ }^{14,15}$ Irisin, the highly conserved fragment of FNDC5, is released into the systemic circulation to exert its most established effect of inducing white adipose tissue browning, activating oxygen consumption, and thermogenesis of fat cells. ${ }^{9,16}$ In addition, irisin may cross the blood-brain barrier to exert its influence in the central nervous system. ${ }^{17}$ Recently, based on preclinical models and clinical evidence, our group has proposed that irisin, by inducing brain-derived neurotrophic factor (BDNF) expression in VTA and hippocampus, may serve as a link between physical activity and reward-related learning and motivation. ${ }^{18} \mathrm{BDNF}$, a neurotrophin, has been associated with reward-related learning and consequent alteration of behavior. ${ }^{19}$ BDNF and its high-affinity receptor tropomyosin-related kinase B are also expressed in the midbrain and hippocampus. ${ }^{12,20,21}$

Motivation and allied reward-related processes are often conceptualized using the reinforcement learning theorem, tied closely to the mesocortico-limbic system. ${ }^{14,15,22}$ Several disorders have been mapped onto the reinforcement learning paradigm including depression, with distinct attributes of value-based decision-making being altered. For example, higher discounting rates for delayed rewards reflective of hopelessness and unwillingness to invest in the future were shown in major depressive disorder. ${ }^{23}$ In a different study, anhedonia, one of the cardinal symptoms of major depressive disorder, was associated with diminished primary sensitivity to rewards. ${ }^{24}$ Accordingly, the dysfunction of VTA-ventral striatum axis has been specifically associated with anhedonia and anergy, also characteristic of depression. ${ }^{25}$

Summarizing, it may be proposed that change of reward processing in mood disorders may be accompanied by alteration in the irisin-BDNF axis. Starting from this hypothesis, we set out to investigate the significant predictors of mood disturbance, with a special focus on the role serum irisin and BDNF play in a cohort of patients suffering from COPD, a disease associated with mental health problems including depressive symptoms.

\section{Methods}

\section{Study design and protocol}

This study was designed in agreement with the STROBE statement for cross-sectional studies ${ }^{26}$ and is in line with the principles established by the Declaration of Helsinki. Approval of the Ethical Committee of the University of Debrecen (DEOEC RKEB/IKEB 3632-2012) was obtained in advance. Informed written consent was obtained from each participant.

In this study, data of our COPD cohort (described previously ${ }^{27}$ ) have been further analyzed. Briefly, every COPD patient, attending the outpatient unit of the Department of Pulmonology (University of Debrecen) between September 1, 2012 and October 15, 2013, for the management of COPD, was screened by attending pulmonologists, who were unaware of the research hypothesis and study protocol. Patients suffering from any acute inflammatory disease over the preceding 1 month and those having benign or malignant tumors in their case history were excluded. Patients meeting the entry criteria were referred to the study nurse who explained the details of the study and obtained informed consent. Every patient referred by the pulmonologists consented to study participation. Overall, 74 COPD patients were recruited. At the time of inclusion, patients were managed for COPD according to the relevant Hungarian practice guideline ${ }^{28}$ and the GOLD initiative. ${ }^{29}$ Airway limitation was defined using the lower limit of normal. ${ }^{30-32}$ Patients received therapy at the time of inclusion as clinically warranted. Whole-body plethysmography was performed for every patient to obtain lung function parameters. Demographic, anthropometric, anamnestic, laboratory, and quality of life data were also acquired. Cumulative measure of smoking exposure was described by pack-years (accounted for both past and current smoking exposure). To assess diseasespecific quality of life, the official Hungarian version of Saint George's Respiratory Questionnaire (SGRQ) ${ }^{33}$ was used with the permission of the proprietor (Paul Jones, University of London, London, UK).

\section{Pulmonary function testing}

Whole-body plethysmography was performed according to the ATS/ERS criteria ${ }^{34,35}$ with Piston whole-body plethysmograph (PDT-111/p; Piston Medical, Budapest, Hungary) equipped with automatic body temperature- and pressuresaturated correction, furthermore, with full automatic calibration and leakage test. Plethysmography was performed while patients were receiving long-term therapy for COPD. The best of three technically sound maneuvers was selected in case of each participant. Regarding resistance curves, at least two separate and technically appropriate measurements were performed (each measurement consists of recordings of at least five resistance loops) and results were accepted only if 
these were the same for both measurements. Of the lung function parameters provided by the whole-body plethysmography, the following data proved to be interesting in this study: airway resistance $\left(\mathrm{R}_{\mathrm{aw}}\right)$, forced expiratory volume in 1 second $\left(\mathrm{FEV}_{1}\right), \mathrm{FEV}_{1}$ as a percent of predicted value $\left(\mathrm{FEV}_{1} \%\right.$ pred $)$, forced vital capacity (FVC) as a percent of predicted value (FVC\% pred), forced expiratory flow between 25\% and $75 \%$ of FVC (FEF25\%-75\%), FEF $25 \%-75 \%$ as a percent of predicted value (FEF25\%-75\% \% pred), residual volume $(\mathrm{RV})$ as a percent of predicted value (RV\% pred), ratio of RV to total lung capacity (TLC) as a percent of predicted value (RV/TLC\% pred). For the statistical analysis, parameters showing Gaussian distribution were used in their raw forms, whereas those not normally distributed were appropriately transformed to obtain normal distribution.

\section{Blood samples and routine laboratory tests}

Blood samples were obtained in the morning of the examination, after an overnight fast. Routine laboratory investigations were performed by the Department of Laboratory Medicine (University of Debrecen) following their standard procedures. Serum or plasma samples were used to characterize carbohydrate homeostasis (glucose, insulin, hemoglobin A1c [HgA1c]), lipid homeostasis (total cholesterol, triglyceride, low-density lipoprotein [LDL] cholesterol, high-density lipoprotein [HDL] cholesterol, lipoprotein (a), apolipoprotein A1 [ApoA1], apolipoprotein B [ApoB], kidney function (glomerular filtration rate [GFR], urea, creatinine), liver function (glutamate-oxaloacetate transaminase, glutamatepyruvate transaminase, gamma-glutamyltransferase), status of skeletal muscles (creatine kinase [CK], lactate dehydrogenase), thyroid-stimulating hormone-sensitive (sTSH), and systemic inflammation (C-reactive protein, procalcitonin, and fibrinogen). From glucose and insulin concentrations, homeostatic model assessment (HOMA) index was calculated as described previously. ${ }^{36}$ Serum samples used to determine irisin and BDNF were frozen within 60 minutes and stored at $-80^{\circ} \mathrm{C}$ until further analysis.

\section{Determination of serum irisin and BDNF} Serum BDNF levels were measured compliant with the manufacturer's instructions (Sigma-Aldrich, St Louis, MO, USA). In short, standards and samples (diluted 100-fold) were administered into 96-well microplates coated with anti-BDNF monoclonal antibody and incubated overnight at $4^{\circ} \mathrm{C}$. Next, plates were washed four times, and then $100 \mu \mathrm{L}$ biotinylated anti-human BDNF detector antibody was added to each well and incubated with gentle shaking for 1 hour. Afterwards, the wells were washed and $100 \mu \mathrm{L}$ of horseradish peroxidase (HRP)-streptavidin solution was added to each well, followed by a 45-minute long incubation period at room temperature with gentle shaking. Samples were washed

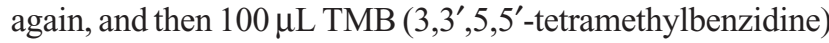
One-Step Substrate Reagent was added to each well and incubation was undertaken for 30 minutes to induce a color reaction. The reaction was stopped with manufacturersupplied stop solution. The absorbance at $450 \mathrm{~nm}$ was measured immediately with an automated microplate reader. All measurements were performed in duplicate. The detection limit for BDNF was $<80 \mathrm{pg} / \mathrm{mL}$.

Serum irisin levels were assayed according to the manufacturer's instructions using a commercially available enzyme-linked immunosorbent assay (ELISA) kit (Phoenix Pharmaceuticals, Burlingame, CA, USA). Briefly, $50 \mu \mathrm{L}$ of standard or sample (diluted two times), $25 \mu \mathrm{L}$ primary antibody, and $25 \mu \mathrm{L}$ biotinylated peptide were added to each well, followed by a 2-hour long incubation period at room temperature. The plates were then washed four times and 100 $\mu \mathrm{L} /$ well SA-HRP solution was added and incubated at room temperature for 1 hour. After washing, $100 \mu \mathrm{L} /$ well of substrate solution was added followed by incubation for 1 hour, after which the reaction was terminated with $100 \mu \mathrm{L} /$ well of $2 \mathrm{~N}$ $\mathrm{HCl}$. Absorbance was read immediately at $450 \mathrm{~nm}$. According to the manufacturer, the irisin standard curve was linear from 1.34 to $29.0 \mathrm{ng} / \mathrm{mL}$, and the detection limit was $1.34 \mathrm{ng} / \mathrm{mL}$.

A standard curve showing linear relationship between optical density and concentration of irisin as well as BDNF was obtained with each plate. For the stratification of the final multiple regression model, serum BDNF levels were dichotomized according to their median value.

\section{St George's Respiratory Questionnaire}

The official Hungarian version of SGRQ validated for a 1-month recall period was used according to the SGRQ manual supplied by the proprietor. ${ }^{37}$ SGRQ quantifies health impairment with three-component scores and one total score. The Symptoms score characterizes the patients' perception of their recent respiratory problems in terms of their effect, frequency, and severity; Activity score quantifies the impairment in daily physical activity; whereas the Impacts score characterizes a wide array of disturbances related to the psycho-social function. Importantly, Impacts score also strongly correlates with disturbances of mood (eg, depression). The Total score sums up the significance of the disease on overall health status. Scores are provided as a 
percentage, thus $100 \%$ indicates the worst and $0 \%$ represents the best subjective health status. Differences in scores were considered clinically meaningful if they exceeded 4 percent points. ${ }^{38}$ Patients filled out the questionnaire by means of supervised self-administration. Two independent raters recorded data by diligently following data entry guidelines, and scoring was done using the score calculation algorithm provided by the developer of the SGRQ. ${ }^{39}$ Inter-rater variability assessed by Spearman correlation was $0.99(P<0.001)$, $0.988(P<0.001), 0.999(P<0.001)$, and $0.999(P<0.001)$ for the Symptoms, Activity, Impacts, and Total scores of SGRQ, respectively. Both raters were blinded to patients' irisin and BDNF levels. For statistical analysis (and data presentation), the mean of scores was computed.

\section{Statistical analysis}

Disturbances of mood were quantified with the Impacts score reflective of mood disorders and overall psycho-social dysfunction.

The mean of the Impacts score was used as cutoff for dichotomization of the COPD cohort, so patients with Impacts score $<32.65 \%$ were put into the lower Impacts score group ( $n=40)$, while patients with Impacts score $\geq 32.65 \%$ formed the higher Impacts score group $(n=34)$, corresponding to less or more pronounced mood disturbances, respectively.

Normality of continuous variables was checked by the Shapiro-Wilk test. For variables following Gaussian distribution, two data sets were compared using Student's $t$-test, whereas Mann-Whitney $U$-test was carried out for those not showing normal distribution. Frequencies were compared with Pearson's $\chi^{2}$ test.

The correlation of mood disturbance and serum irisin concentration was established using Spearman's correlation. The relationship between mood disturbance and serum irisin level was further investigated with simple as well as multiple linear regression. To ensure normal distribution of variables for these analyses, $\mathrm{CK}$, total cholesterol, triglyceride, LDL cholesterol, HDL cholesterol, ApoA1, ApoB, insulin, HgA1c, sTSH, HOMA index, FEF25\%-75\%, RV, and $\mathrm{RV} \%$ pred were log-transformed; furthermore, square root of disease duration, reciprocal of irisin, and reciprocal of square of glucose concentration were computed.

Simple linear regression was carried out with traditional confounding factors (age, gender, height, and disease duration in years), lung function parameters, and routine laboratory parameters obtained from the serum or plasma samples. Missing data were omitted. To eliminate the effects of potential confounders, multiple linear regression modeling was performed.
First, the least parsimonious multiple model was compiled including all significant regressors identified by means of simple linear regression and a priori variables (age and gender). Variables were introduced into the initial multiple model simultaneously, and then factors not contributing significantly to the model were deleted (except for the a priori variables). The final model contained (in addition to the a priori parameters) $\mathrm{FEV}_{1} \%$ pred, body mass index, weight, and (log) triglyceride levels. Furthermore, the final model was stratified with respect to BDNF levels. Heteroskedasticity and goodness of fit for the model were assessed by Cook-Weisberg and Ramsey test.

Statistical analysis was performed with Stata 13.0 software StataCorp. 2013. Stata Statistical Software: Release 13. College Station, TX: StataCorp LP). Values are given as mean \pm SD or median (with the interquartile range: IQR), and regression coefficients are presented with their 95\% confidence interval $(95 \% \mathrm{CI})$.

\section{Results}

\section{Patients}

The baseline characteristics of our COPD patient cohort were detailed previously. ${ }^{27}$ Demographic, anthropometric characteristics, medication history, pulmonary function, and disease-specific health impairment measures are summarized in Table 1.

\section{Comparison of patients with respect to mood disturbance}

The two groups of COPD patients, dichotomized with respect to the mean of Impacts score, proved to be homogeneous regarding most of the parameters investigated. Nevertheless, in the group with higher Impacts score (showing more pronounced impairment of mood), dyslipidemia, and hypertension (as anamnestic data) were more frequent; serum LDL cholesterol, serum irisin, $\mathrm{FEV}_{1} \%$ pred, and $\mathrm{FVC} \%$ pred were significantly lower; whereas serum glucose was significantly higher than the corresponding values in the group with lower Impacts score (showing less despair) (Table 2).

\section{Associations among SGRQ's Impacts score, serum irisin, and BDNF levels}

Upon assessing the correlation between the Impacts score and reciprocal of irisin, we found a significant positive correlation in the whole COPD cohort (Spearman correlation coefficient: $0.26, P=0.02$; Figure 1), in agreement with the finding that irisin concentration was smaller in the higher Impacts score group (Table 2). This correlation became stronger (and remained almost statistically significant) in the 
Table I Main characteristics of the whole COPD cohort $(n=74)$

\begin{tabular}{|c|c|}
\hline Parameters & Data \\
\hline Age (years) & $62.15 \pm 9.70$ \\
\hline Gender (female/male) & $27 / 47$ \\
\hline Smoker & $25 / 74(33.8 \%)$ \\
\hline Smoking (pack-years) & $20.00(5.25-33.75)$ \\
\hline Smoking (years) & $10.00(0.00-33.00)$ \\
\hline Diabetes present & $13 / 74(17.6 \%)$ \\
\hline Dyslipidemia present & $26 / 74(35.1 \%)$ \\
\hline Hypertension present & $43 / 74(58.1 \%)$ \\
\hline Disease duration (years) & $5.00(3.00-10.00)$ \\
\hline Waist (cm) & $101.99 \pm \mid 4.31$ \\
\hline Weight (kg) & $79.71 \pm 17.12$ \\
\hline Height (m) & $1.68 \pm 0.094$ \\
\hline BMI $\left(\mathrm{kg} / \mathrm{m}^{2}\right)$ & $28.19 \pm 5.09$ \\
\hline Irisin (ng/mL) & $7.22(6.63-8.10)$ \\
\hline BDNF (ng/mL) & $345.6(294.20-387.90)$ \\
\hline CK (U/L) & $101.00(74.00-139.00)$ \\
\hline LDH (U/L) & $208.62 \pm 34.98$ \\
\hline Glucose (mmol/L) & $5.00(4.20-5.80)$ \\
\hline Insulin (mU/L) & $8.95(5.55-16.50)$ \\
\hline $\mathrm{HgAIC}(\%)$ & $5.70(5.50-6.10)$ \\
\hline HOMA index & $2.14(1.14-4.67)$ \\
\hline Cholesterol (mmol/L) & $5.30(4.00-6.30)$ \\
\hline LDL-C (mmol/L) & $3.10(2.60-3.70)$ \\
\hline HDL-C (mmol/L) & $1.40(1.20-1.80)$ \\
\hline Triglyceride (mmol/L) & $1.35(1.00-2.00)$ \\
\hline $\mathrm{CRP}(\mathrm{mg} / \mathrm{L})$ & $2.00(1.21-4.00)$ \\
\hline Fibrinogen $(g / L)$ & $3.67(3.25-4.00)$ \\
\hline Procalcitonin $(\mu \mathrm{g} / \mathrm{L})$ & $0.00(0.00-0.00)$ \\
\hline SGRQ Symptoms score & 32.66 (I3.64-58.28) \\
\hline SGRQ Impacts score & 29.64 (I5.44-49.79) \\
\hline SGRQ Activity score & $57.32(47.24-72.08)$ \\
\hline SGRQ Total score & $41.08 \pm 20.99$ \\
\hline $\mathrm{FEV}_{1}(\mathrm{~L} / \mathrm{s})$ & $1.86 \pm 0.72$ \\
\hline $\mathrm{FEV}, \%$ pred & $66.54 \pm 20.29$ \\
\hline FEF25\%-75\% (L/s) & $1.18(0.65-1.8 I)$ \\
\hline FEF $25 \%-75 \% \%$ pred & $35.50(24.00-55.00)$ \\
\hline $\mathrm{RV} / \mathrm{TLC}$ & $54.45 \pm 10.08$ \\
\hline RV/TLC\% pred & $|39.97 \pm 2| .27$ \\
\hline FVC (L) & $2.75(2.23-3.39)$ \\
\hline FVC\% pred & $82.54 \pm 17.44$ \\
\hline $\mathrm{R}_{\mathrm{aw}}(\mathrm{kPa} \cdot \mathrm{s} / \mathrm{L})$ & $0.27(0.22-0.42)$ \\
\hline
\end{tabular}

Note: Data are presented as mean \pm SD or median (interquartile range) unless otherwise stated.

Abbreviations: BDNF, brain-derived neurotrophic factor; BMI, body mass index; CK, creatine kinase; CRP, C-reactive protein; FEV , forced expiratory volume in I second; FVC, forced vital capacity; HDL, high-density lipoprotein; HOMA, homeostatic model assessment; LDH, lactate dehydrogenase; LDL, low-density lipoprotein; RV, residual volume; SD, standard deviation; SGRQ, St George's Respiratory Questionnaire; TLC, total lung capacity.

stratum with lower BDNF level, while it was weaker (and non-significant) in the stratum with higher BDNF (Spearman correlation coefficient: 0.32 and $0.22, P=0.055$ and 0.19 , respectively).

When the relationship between the Impacts score and reciprocal of serum irisin level was analyzed with simple linear regression, the regression coefficient failed to reach statistical significance ( $P=0.08$; Table 3$)$. However, after adjusting for all significant predictors and a priori determinants by means of multiple linear regression, the Impacts score and reciprocal of irisin showed a strong, significant, positive association ( $\beta$ : 419.97; 95\% CI: 204.31, 635.63; $P<0.001$ ) (Table 4). This association became even more distinct among patients with lower BDNF levels ( $\beta$ : 434.11; 95\% CI: $166.17,702.05 ; P=0.002$ ), while a considerably weaker and statistically nonsignificant association was present in case of patients with higher BDNF concentrations ( $\beta$ : 373.49; 95\% CI: $-74.91,821.88 ; P=0.10)$. All three models were significant $(P<0.001,0.001$, and 0.009$)$ (Table 5). The Cook-Weisberg test showed no heteroskedasticity for the full model and strata with lower and higher BDNF ( $P=0.92$, 0.67 , and 0.82 , respectively). Furthermore, all three models showed good fit reflected by the locally weighted scatterplot smoothing (Figure 2 ) as well as by the Ramsey test $(P=0.82$; 0.53 , and 0.79 for the whole data set and strata with lower and higher BDNF, respectively).

Based on the final multiple linear regression model (built for the Impacts score), body mass index, log triglyceride, and body weight were significantly associated with mood disturbances among COPD patients. In addition, severity of airflow limitation, characterized by $\mathrm{FEV}_{1} \%$ pred, showed a significant negative association with the Impacts score ( $\beta$ : $-0.52 ; 95 \%$ CI: $-0.71,-0.32 ; P<0.001$ ) (Table 4 ).

\section{Discussion}

The main finding of this study is that the reciprocal of serum irisin level shows significant positive correlation with the Impacts score of SGRQ in COPD patients. Thus, more pronounced disturbance of mood (indicated by higher Impacts score) is accompanied by lower irisin levels. This effect has proven even more prominent among patients with lower BDNF levels, but became nonsignificant in patients possessing higher BDNF concentrations. Analysis by means of multiple linear regression that corrects for possible confounders has confirmed the significant association between Impacts score and serum irisin; furthermore, it also revealed four other significant determinants of Impacts score: BMI, weight, triglyceride level, and $\mathrm{FEV}_{1} \%$ pred, an index of the severity of airflow limitation in COPD. ${ }^{29}$

Several studies have corroborating evidence for the relationship between markers of disease severity and BMI. Recently, the COPD Gene investigators analyzed the data of 3,631 spirometry-confirmed COPD patients obtained from a multicenter prospective cohort study. The investigators found 
Table 2 Main characteristics of two groups of the COPD cohort dichotomized according to mood disturbances indicated by the Impacts score

\begin{tabular}{|c|c|c|c|}
\hline Parameters & Lower Impacts score & Higher Impacts score & $P$-value \\
\hline Age (years) & $62.75 \pm 9.15$ & $61.44 \pm 10.40$ & 0.567 \\
\hline Gender (female/male) & $12 / 28$ & $15 / 19$ & 0.209 \\
\hline Smoker & $13 / 40$ (32.5\%) & I2/34 (35.3\%) & 0.800 \\
\hline Smoking (pack-years) & $19(2.25-33)$ & $20(8.8-37.5)$ & 0.227 \\
\hline Smoking (years) & $5.50(0.00-30.00)$ & $12.50(0.00-38.00)$ & 0.460 \\
\hline Diabetes present & $5 / 40(12.5 \%)$ & $8 / 34(23.5 \%)$ & 0.214 \\
\hline Dyslipidemia present & $9 / 40(22.5 \%)$ & I7/34 (50.0\%) & 0.017 \\
\hline Hypertension present & I8/40 (45.0\%) & $25 / 34(73.5 \%)$ & 0.013 \\
\hline RR systolic (mmHg) & $135.45 \pm 15.34$ & $137.70 \pm 16.60$ & 0.545 \\
\hline $\mathrm{RR}$ diastolic $(\mathrm{mmHg})$ & $83.00 \pm 14.62$ & $81.65 \pm 13.60$ & 0.683 \\
\hline Prior AMI & $4 / 40(10.0 \%)$ & $5 / 34(14.7 \%)$ & 0.538 \\
\hline Prior stroke $(\mathrm{n} / \mathrm{y})$ & $0 / 40(0 \%)$ & $\mathrm{I} / 34(2.9 \%)$ & 0.275 \\
\hline Disease duration (years) & $5.00(3.00-8.00)$ & $6.00(3.00-10.00)$ & 0.301 \\
\hline Waist (cm) & $101.11 \pm 13.04$ & $103.02 \pm 15.81$ & 0.570 \\
\hline Weight (kg) & $78.77 \pm|5.4|$ & $80.81 \pm 19.13$ & 0.617 \\
\hline Height (m) & $1.70 \pm 0.94$ & $1.65 \pm 0.10$ & 0.110 \\
\hline BMI $\left(\mathrm{kg} / \mathrm{m}^{2}\right)$ & $27.29 \pm 4.25$ & $29.25 \pm 5.82$ & 0.103 \\
\hline Irisin (ng/mL) & $7.37(6.99-8.12)$ & $6.85(6.49-7.99)$ & 0.030 \\
\hline BDNF (ng/mL) & $347.55(316.10-4 \mid 3.60)$ & $343.15(292.00-377.90)$ & 0.400 \\
\hline Urea (mmol/L) & $5.31 \pm 1.30$ & $5.3 \mathrm{I} \pm \mathrm{I} .47$ & 0.995 \\
\hline Creatinine $(\mu \mathrm{mol} / \mathrm{L})$ & $69.50(57.50-81.50)$ & $72.00(61.00-80.00)$ & 0.840 \\
\hline GFR $\left(\mathrm{mL} / \mathrm{min} / \mathrm{l} .73 \mathrm{~m}^{2}\right)$ & $90.00(81.50-91.00)$ & 91.00 (80.00-91.00) & 0.920 \\
\hline GOT (U/L) & $20.00(16.00-24.00)$ & $19.00(15.00-22.00)$ & 0.384 \\
\hline GPT (U/L) & $20.50(14.50-29.50)$ & $1.00(\mid 3.00-21.00)$ & 0.102 \\
\hline$\gamma \mathrm{GT}(\mathrm{U} / \mathrm{L})$ & $32.50(19.50-49.00)$ & $32.50(20.00-47.00)$ & 0.724 \\
\hline CK (U/L) & $101.50(77.50-138.50)$ & $93.50(73.00-147.00)$ & 0.640 \\
\hline $\mathrm{LDH}(\mathrm{U} / \mathrm{L})$ & $207.55 \pm 36.08$ & $209.88 \pm 34.12$ & 0.780 \\
\hline Glucose $(\mathrm{mmol} / \mathrm{L})$ & $4.08(4.00-5.50)$ & $5.30(4.70-6.60)$ & 0.015 \\
\hline Insulin (mU/L) & $7.50(5.30-13.50)$ & $9.45(5.90-22.40)$ & 0.243 \\
\hline $\mathrm{HgAlc}(\%)$ & $5.70(5.45-6.00)$ & $5.70(5.50-6.20)$ & 0.550 \\
\hline HOMA index & $1.48(1.00-3.38)$ & $2.35(1.46-5.92)$ & 0.092 \\
\hline Cholesterol (mmol/L) & $5.70(4.00-6.30)$ & $5.00(4.00-5.80)$ & 0.112 \\
\hline LDL-C (mmol/L) & $3.25(2.65-4.00)$ & $2.80(2.40-3.30)$ & 0.030 \\
\hline $\mathrm{HDL}-\mathrm{C}(\mathrm{mmol} / \mathrm{L})$ & $1.45(1.20-1.80)$ & $1.35(1.00-1.80)$ & 0.570 \\
\hline Triglyceride $(\mathrm{mmol} / \mathrm{L})$ & $1.35(0.95-1.95)$ & $1.35(1.00-2.00)$ & 0.691 \\
\hline CRP (mg/L) & $1.90(0.85-3.65)$ & $2.60(1.50-7.00)$ & 0.060 \\
\hline Fibrinogen $(g / L)$ & $3.63(3.13-4.00)$ & $3.69(3.33-4.00)$ & 0.543 \\
\hline Procalcitonin $(\mu g / L)$ & $0.00(0.00-0.00)$ & $0.00(0.00-0.00)$ & 0.360 \\
\hline $\mathrm{sTSH}(\mathrm{mU} / \mathrm{L})$ & $1.36(0.84-2.00)$ & $1.12(0.78-1.43)$ & 0.216 \\
\hline $\mathrm{FEV}_{1} \%$ pred & $71.37 \pm 19.26$ & $60.85 \pm 20.25$ & 0.025 \\
\hline FVC\% pred & $86.3 \pm 16.92$ & $78.12 \pm 17.25$ & 0.043 \\
\hline
\end{tabular}

Notes: Patients in the lower and higher Impacts score groups had smaller and higher (or equal) Impacts score than (or to) $32.65 \%$, respectively, with $32.65 \%$ being the mean Impacts score of the whole cohort. Data are presented as mean \pm SD or median (interquartile range), unless otherwise stated. Differences between the two groups were considered significant at $P<0.05$ (indicated in bold).

Abbreviations: AMI, acute myocardial infarction; BDNF, brain-derived neurotrophic factor; BMI, body mass index; CK, creatine kinase; CRP, C-reactive protein; FEV , forced expiratory volume in I second; FVC, forced vital capacity; GFR, glomerular filtration rate; GOT, glutamate-oxaloacetate transaminase; GPT, glutamate-pyruvate transaminase; HDL, high-density lipoprotein; HOMA, homeostatic model assessment; LDH, lactate dehydrogenase; LDL, low-density lipoprotein; RR, blood pressure measured according to Riva-Rocci; sTSH, thyroid-stimulating hormone-sensitive; $\gamma \mathrm{GT}$, gamma-glutamyltransferase.

significant association between obesity, characterized by higher BMI and worse outcomes including poorer quality of life, dyspnea, and reduced 6-minute walk distance. Furthermore, greater odds for acute exacerbations were observed, independent of the presence of comorbidities. ${ }^{40}$ Furthermore, Ho et $\mathrm{al}^{41}$ have also reported significant correlation between
$\mathrm{FEV}_{1} \%\left(\mathrm{FEV}_{1} / \mathrm{FVC}\right)$ and BMI (Spearman's correlation coefficient $0.255, P<0.01$ ). In another study, the influence of metabolic syndrome and its components on the 5-year mortality was assessed in COPD. The authors found that $100 \mathrm{mg} / \mathrm{dL}$ increase of plasma triglyceride concentration increases the probability of death over the 5 years by $39 \%$ 


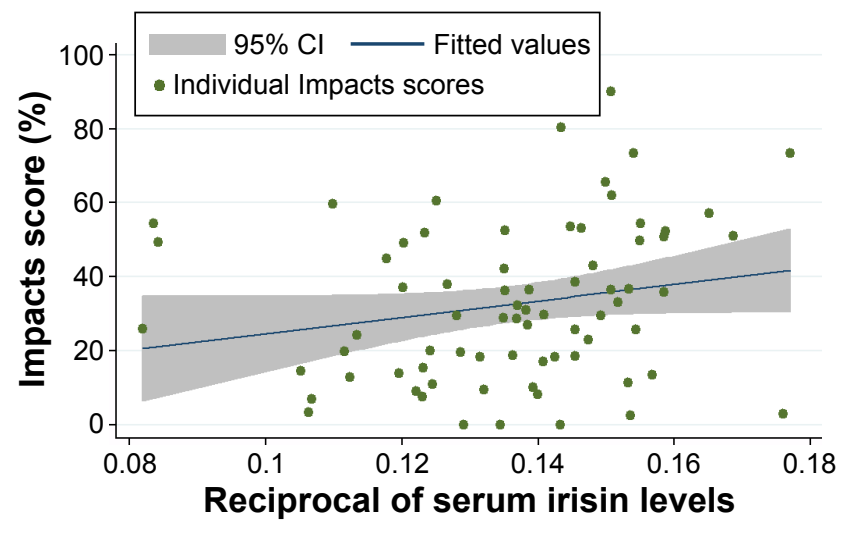

Figure I Correlation of mood disturbance (characterized by the Impacts score of SGRQ) and reciprocal of serum irisin concentration in the whole data set $(n=74)$.

Notes: The $x$-axis shows the reciprocal of serum irisin level (in $n g / m L$ ), whereas the $y$-axis denotes the Impacts score of SGRQ. The blue line shows the fitted line to the data points (represented by the green dots), whereas the grey zone indicates the $95 \% \mathrm{Cl}$.

Abbreviations: $\mathrm{Cl}$, confidence interval; SGRQ, St George's Respiratory Questionnaire.

(translating into a hazard ratio of $1.39,95 \% \mathrm{CI}: 1.06,1.83){ }^{42}$ This finding corroborates our result that log triglyceride levels were significantly associated with the Impacts score in our final multiple linear regression model (Table 4). Moreover, the possibility for a common pathomechanism of COPD and depressive disorders was also suggested based on the results of an interventional study. Patients were enrolled in a complex exercise program ( 2 hours per day, 5 days per week, for 6 weeks) supervised by physiotherapists and lung specialists. At follow-up, improvement of depressive symptoms paralleled by significant reduction of BMI was reported in the subgroup of patients showing signs of depression at baseline..$^{43}$ These findings could be explained by our proposition that exercise-induced increase in irisin levels may simultaneously induce white adipocyte browning and consequent weight loss and enhance mood via activation of the BDNF pathway in specific brain areas (eg, hippocampus, VTA) involved in affective disorders.

Prognostic value of $\mathrm{FEV}_{1} \%$ pred regarding populationlevel clinical outcomes is acknowledged by the Global Strategy for the Diagnosis, Management, and Prevention of Chronic Obstructive Pulmonary Disease (2017 report). ${ }^{44}$ $\mathrm{FEV}_{1} \%$ pred is also predictive of health status and the rate of exacerbations in COPD and it is closely interconnected with alteration of mood and psychosocial function. ${ }^{30}$ The significant inverse relationship between Impacts score and $\mathrm{FEV}_{1} \%$ pred is also in line with previous findings. Significant negative correlation between $\mathrm{FEV}_{1} \%$ pred and all components (Symptoms, Impacts, Activity) and the total score of SGRQ was previously described in a cohort of Hispanic smokers. ${ }^{45}$
Table 3 Significant predictors of reciprocal of serum irisin level and Impacts score of SGRQ determined with simple linear regression for the whole COPD cohort $(n=74)$

\begin{tabular}{|c|c|c|}
\hline Parameter & Coefficient $(95 \% \mathrm{Cl})$ & $P$-value \\
\hline \multicolumn{3}{|c|}{ Simple linear regression of reciprocal of irisin } \\
\hline Waist circumference & $0.00045(0.00015,0.00075)$ & 0.004 \\
\hline Weight & $0.00027(0.00002,0.00052)$ & 0.036 \\
\hline $\begin{array}{l}\text { Reciprocal of glucose } \\
\text { square }\end{array}$ & $-0.31(-0.56,-0.06)$ & 0.014 \\
\hline Log HgAlc & $0.043(0.008,0.077)$ & 0.016 \\
\hline Urea & $0.0035(0.00027,0.0068)$ & 0.034 \\
\hline LDH & $-0.00014\left(-0.00026,-9.94 \cdot 10^{-6}\right)$ & 0.035 \\
\hline Log triglyceride & $0.011(0.0033,0.019)$ & 0.006 \\
\hline Log HDL cholesterol & $-0.022(-0.035,-0.008)$ & 0.002 \\
\hline FVC & $0.006 \mathrm{I}(0.00084,0.0 \mathrm{II})$ & 0.024 \\
\hline $\mathrm{FEV}_{1}$ & $0.0068(0.0006,0.013)$ & 0.032 \\
\hline RV/TLC\% pred & $-0.0023(-0.00043,-0.00002)$ & 0.03 \\
\hline \multicolumn{3}{|c|}{ Simple linear regression of Impacts score } \\
\hline Height & $-57.86(-109.01,-6.65)$ & 0.027 \\
\hline Sqrt of disease duration & $5.52(0.89,9.58)$ & 0.019 \\
\hline $\begin{array}{l}\text { Reciprocal of glucose } \\
\text { square }\end{array}$ & $-369.63(-635.69,-103.58)$ & 0.007 \\
\hline Log HgAlc & $44.97(7.58,82.37)$ & 0.019 \\
\hline CRP & $0.95(0.19,1.72)$ & 0.015 \\
\hline Log cholesterol & $-2 I .4 I(-39.2 I,-3.6 I)$ & 0.019 \\
\hline Log LDL cholesterol & $-15.56(-28.7,-2.42)$ & 0.021 \\
\hline Log HOMA index & $5.82(1.29,10.56)$ & 0.012 \\
\hline BMI & $1.16(0.23,2.1)$ & 0.016 \\
\hline Log sTSH & $-9.89(-17.35,-2.43)$ & 0.01 \\
\hline FVC & $-10.04(-15.36,-4.73)$ & $<0.001$ \\
\hline FVC\% pred & $-0.39(-0.66,-0.12)$ & 0.005 \\
\hline $\mathrm{FEV}_{1}$ & $-12.24(-18.5,-5.99)$ & $<0.001$ \\
\hline $\mathrm{FEV}, \%$ pred & $-0.38(-0.61,-0.15)$ & 0.001 \\
\hline FEF25\%-75\% & $-7.01(-12.96,-1.06)$ & 0.022 \\
\hline Log FEF25\%-75\% \% pred & $-9.45(-17.91,-1)$ & 0.029 \\
\hline RV/TLC & $0.62(0.15,1.08)$ & 0.01 \\
\hline RV/TLC\% pred & $0.34(0.12,0.55)$ & 0.03 \\
\hline
\end{tabular}

Note: Regression coefficient values are presented with their $95 \% \mathrm{Cl}$.

Abbreviations: $\mathrm{BMI}$, body mass index; $\mathrm{Cl}$, confidence interval; $\mathrm{CRP}, \mathrm{C}$-reactive protein; $\mathrm{FEV}_{1}$, forced expiratory volume in I second; FVC, forced vital capacity; HDL, high-density lipoprotein; HOMA, homeostatic model assessment; LDH, lactate dehydrogenase; LDL, low-density lipoprotein; RV, residual volume; SGRQ, St George's Respiratory Questionnaire; SQRT, square root; TLC, total lung capacity; sTSH, thyroid-stimulating hormone-sensitive.

Similarly, in another study, significant negative correlation between $\mathrm{FEV}_{1} \%$ pred and the Total score was described in a sample of severe COPD patients $(r=-0.4, P<0.001){ }^{46}$ In a double-blind placebo-controlled study designed to assess the benefits of the fixed combination inhaler fluticasone propionate and salmeterol versus placebo, the longitudinal analysis of data for 4,951 COPD patients showed significant negative correlation regarding the change in SGRQ scores and $\mathrm{FEV}_{1}$ during the 3 years of the study in all treatment arms, combined. ${ }^{47}$ Previously, we also found a significant negative correlation between the Total SGRQ score and $\mathrm{FEV}_{1} \%$ pred. ${ }^{27}$ 
Table 4 Multiple linear regression model for the SGRQ's Impacts score of the whole COPD cohort and its strata with respect to the median BDNF level

\begin{tabular}{|c|c|c|}
\hline Parameter & Coefficient $(95 \% \mathrm{CI})$ & $P$-value \\
\hline \multicolumn{3}{|l|}{ Whole cohort } \\
\hline Reciprocal of irisin & $419.97(204.31,635.63)$ & 0.000 \\
\hline Age & $-0.42(-0.85,0.01)$ & 0.053 \\
\hline Gender & $0.45(-9.92,10.83)$ & 0.931 \\
\hline $\mathrm{FEV}, \%$ pred & $-0.52(-0.7 I,-0.32)$ & 0.000 \\
\hline BMI & $3.68(2.01,5.34)$ & 0.000 \\
\hline Log triglyceride & $-8.70(-16.38,-1.02)$ & 0.027 \\
\hline Weight & $-0.78(-1.31,-0.25)$ & 0.004 \\
\hline \multicolumn{3}{|c|}{ Lower BDNF stratum } \\
\hline Reciprocal of irisin & $434.11(166.17,702.05)$ & 0.002 \\
\hline Age & $-0.39(-0.94,0.16)$ & 0.160 \\
\hline Gender & $-3.87(-23.46,15.72)$ & 0.689 \\
\hline FEV,$\%$ pred & $-0.50(-0.76,-0.23)$ & 0.001 \\
\hline BMI & $3.45(0.49,6.42)$ & 0.024 \\
\hline Log triglyceride & $-|1.9|(-22.31,-1.50)$ & 0.026 \\
\hline Weight & $-0.58(-1.60,0.43)$ & 0.250 \\
\hline \multicolumn{3}{|c|}{ Higher BDNF stratum } \\
\hline Reciprocal of irisin & 373.49 (-74.9I, 82I.88) & 0.099 \\
\hline Age & $-0.49(-1.38,0.40)$ & 0.269 \\
\hline Gender & $1.19(-15.55,17.94)$ & 0.885 \\
\hline $\mathrm{FEV}, \%$ pred & $-0.56(-0.93,-0.19)$ & 0.004 \\
\hline BMI & $3.70(1.25,6.15)$ & 0.005 \\
\hline Log triglyceride & $-4.62(-18.32,9.07)$ & 0.494 \\
\hline Weight & $-0.83(-1.59,-0.07)$ & 0.033 \\
\hline
\end{tabular}

Notes: Regression coefficient values are presented with their $95 \% \mathrm{Cl}$. The initial model for the multiple linear regression analysis consisted of the significant parameters provided by the simple linear regression and the relevant a priori identified parameters (age, gender). $P$-values $<0.05$ are indicated in bold.

Abbreviations: BDNF, brain-derived neurotrophic factor; BMI, body mass index; $\mathrm{Cl}$, confidence intervals; $\mathrm{FEV}$, forced expiratory volume in I second; SGRQ, St George's Respiratory Questionnaire.

Our present analysis showed a very strong positive association between the Impacts score, reflective of depressive mood disturbances in COPD and the reciprocal of serum irisin (Table 4) that was substantially more remarkable in the stratum with BDNF levels lower than the sample median. In addition to reciprocal of irisin, regression coefficients remained significant for $\mathrm{FEV}_{1} \%$ pred, $\mathrm{BMI}$, and log triglyceride in the stratum with lower BDNF levels. However, only $\mathrm{FEV}_{1} \%$ pred, BMI, and weight showed significant contribution to the final model in the stratum with higher BDNF levels (Table 4). These results suggest the presence of an interaction between serum irisin and serum BDNF levels regarding their influence on Impacts score and they underscore our previous hypothesis that serum irisin may exert a peripheral effect reflected by the alteration of metabolic parameters (BMI, weight, and serum triglyceride levels) and a central effect related to mood and motivation based on BDNF's action.

The role of BDNF in depressive disorders has been articulated by the neurotrophic hypothesis of depression.
Table 5 ANOVA tables describing the final model for the whole cohort (Panel A), lower BDNF stratum (Panel B), and higher BDNF stratum (Panel C)

\begin{tabular}{lllll}
\hline Panel & SS & df & MS & \\
\hline A & & & & \\
Model & $15,192.92$ & 7 & $2,170.42$ & $\mathrm{~N}=72$ \\
Residual & $15,875.15$ & 64 & 248.05 & $\mathrm{~F}(7,64)=8.75$ \\
Total & $31,068.07$ & $7 \mathrm{I}$ & 437.58 & $\mathrm{P}<0.00 \mathrm{I}$ \\
& & & & $R^{2}=0.489$ \\
& & & & $\mathrm{Adj} R^{2}=0.433$ \\
& & & & Root MSE $=15.75$ \\
B & & & & \\
Model & $7,877.75$ & 7 & $\mathrm{I}, 125.39$ & $\mathrm{~N}=37$ \\
Residual & $6,880.71$ & 29 & 237.27 & $\mathrm{~F}(7,29)=4.74$ \\
Total & $14,758.46$ & 36 & 409.96 & $\mathrm{P}=0.0012$ \\
& & & & $R^{2}=0.534$ \\
& & & & $\mathrm{Adj} R^{2}=0.421$ \\
C & & & & $\mathrm{Root} \mathrm{MSE}=15.40$ \\
Model & $7,576.25$ & 7 & $\mathrm{I}, 082.32$ & $\mathrm{~N}=35$ \\
Residual & $8,545.32$ & 27 & 316.49 & $\mathrm{~F}(7,29)=3.42$ \\
Total & $16,121.57$ & 34 & 474.16 & $\mathrm{P}=0.0095$ \\
& & & & $R^{2}=0.4699$ \\
& & & & $\mathrm{Adj} R^{2}=0.3325$ \\
& & & & $\operatorname{Root} \mathrm{MSE}=17.79$ \\
& & & &
\end{tabular}

Note: Data regarding the weight of two patients were missing; thus, they were not included in the analysis.

Abbreviations: ANOVA, analysis of variance; BDNF, brain-derived neurotrophic factor; df, degree of freedom; MS, mean of the sum of squares; MSE, mean squares of error; SS, sum of squares.

According to this, depression is based on neurotrophin deficiency of the limbic system, an effect that may be reversed by long-term administration of antidepressants. ${ }^{48,49}$ This hypothesis is closely linked to the neural plasticity hypothesis, which postulates that environmental factors (eg, stress)

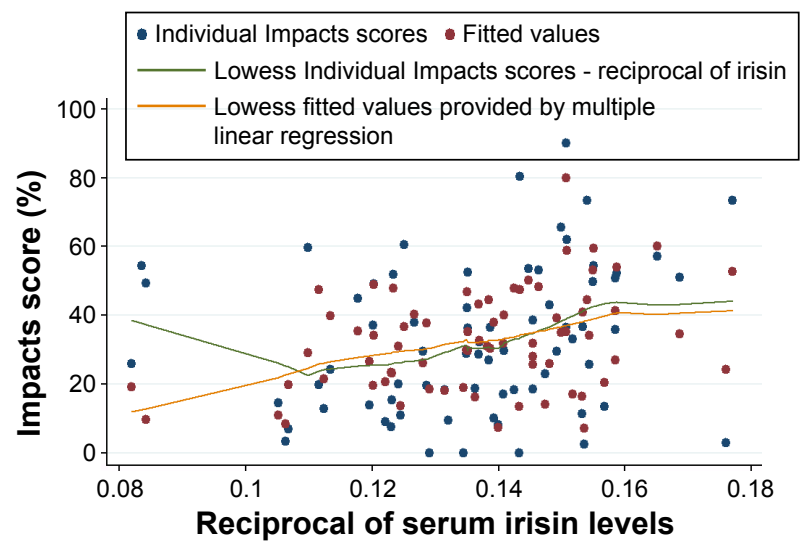

Figure 2 The model describing the correlation between the Impacts score of SGRQ and reciprocal of serum irisin concentration in the whole data set $(n=74)$.

Notes: The $x$-axis shows the reciprocal of serum irisin concentration (in $\mathrm{ng} / \mathrm{mL}$ ), whereas the $y$-axis denotes the Impacts score of SGRQ. The blue and red dots indicate the raw and fitted values obtained by multiple linear regression, respectively. The green and orange lines indicate the curves fitted to the raw data and to data provided by multiple linear regression. Fitting was done by locally weighted scatterplot smoothing (lowess).

Abbreviation: SGRQ, St George's Respiratory Questionnaire. 
cause dysfunction of signal transduction cascades involved in neuronal adaptation and plasticity. A candidate pathway is that containing BDNF-cAMP response element-binding protein, a transcription factor. ${ }^{49}$

Changes in BDNF plasma levels as well as tissue levels from postmortem biopsies of hippocampus have been described in depressed patients. ${ }^{49}$ Furthermore, the causeeffect relationship between BDNF and major depressive disorder was established by a case-control study nested in a cohort of 1,276 women aged 75-84 years. Using incident cases and controls over the 4-year observation period, the authors concluded that BDNF is a state marker of major depressive disease based on the longitudinal decrease of serum BDNF levels in this cohort. ${ }^{50}$ Corroborating evidence from a systematic review and meta-analysis of 20 publications including 1,504 participants, furthermore, showed significant correlation between changes of BDNF level and depression score as well as significant increases of BDNF levels accompanied therapy with antidepressants. ${ }^{51}$ Nevertheless, it should be noted that, despite the accumulating preclinical and clinical evidence, there are some controversies related to the role BDNF plays in the evolution of depression, as inconsistent observations questioning this hypothesis were also reported. ${ }^{52,53}$ However, these discrepancies may stem from the methodological differences like variance of patient populations, sample size, treatment schedules, disease severity, and assessment tools quantifying disease severity. ${ }^{52}$

To the best of our knowledge, this is the first time that the irisin-BDNF axis was assessed with respect to its possible influence on mood disturbances in COPD patients. The ability of exercise to induce BDNF expression in the hippocampus via induction of the FNDC5-irisin pathway has been reported previously in mice. ${ }^{12}$ Our present results seem to support these findings in humans for the first time.

Limited number of reports deals with the alteration of serum irisin and BDNF levels in COPD patients. Irisin levels were shown to be lower in COPD patients than in controls (31.6 [IQR: 22.7-40.4] ng/mL and 50.7 [IQR: $39.3-65.8] \mathrm{ng} / \mathrm{mL}$, respectively; $P<0.001) .{ }^{54}$ This tendency was present even when patients were divided into subgroups with respect to the level of physical activity: in patients with lower physical activity, serum irisin levels were 23.1 (IQR: 17.3-27.0) $\mathrm{ng} / \mathrm{mL}$ and 39.6 (IQR: $36.0-43.7$ ) $\mathrm{ng} / \mathrm{mL}$ in COPD and control patients, respectively. ${ }^{54}$ Others reported comparable irisin levels of 26.3 (IQR: $22.6-32.4) \mathrm{ng} / \mathrm{mL}$, 53.7 (IQR: 46.7-62.8) ng/mL, and 58.5 (42.8-78.9) ng/mL in smokers with and without COPD and in non-smoking individuals, respectively. ${ }^{55}$ While the serum BDNF levels measured in our study are higher than those in the study of Stoll et al that included COPD patients, ${ }^{56}$ they are within the magnitude measured in other studies involving healthy individuals and other patient populations. The reported serum BDNF levels span over five orders of magnitude, ranging from 0.005 to $280 \mathrm{ng} / \mathrm{mL},{ }^{50,52,57,58}$ depending on the use of different ELISA kits.

A possible limitation of this study comes from its design (cross-sectional study), limiting the possibility to draw cause and effect conclusions. Due diligence was exercised to counterbalance the effect of possible confounders by using multiple linear regression to account for their effect. Characterizing disturbance of mood by the Impacts component score of the SGRQ may also be viewed as a possible shortcoming. Identification of depression based on the Diagnostic and Statistical Manual of Mental Disorders 5 may prove to be challenging as accompanying somatic symptoms could be secondary to either depression or COPD. ${ }^{43}$ Furthermore, utility of certain diagnostic instruments, for example, hospital anxiety and depression scale, has been questioned with respect to their accuracy in COPD patients. ${ }^{59}$ Nevertheless, strong correlation between the Impacts score and depression has been described previously, ${ }^{8,60}$ allowing us to propose that irisin is a possible link between both metabolic disturbances and affective changes. The absence of postbronchodilator whole-body plethysmography may also be viewed as a limitation; however, as previously described, ${ }^{27}$ this patient population has been included in a COPD management program for a median of 5 (IQR: 3-10) years, hence patients already received bronchodilator therapy and were asked to take their medications as usual in the morning of the examinations. Thus, the current results should be interpreted as on-treatment results. Summarizing, future prospective studies are needed to further underscore the propositions laid out in our current work. Nevertheless, this investigation has several merits like the relatively large clinical patient sample, the use of special tools (whole-body plethysmography and SGRQ, a validated disease-specific questionnaire), furthermore, the stringent data analysis resulting in powerful findings.

In summary, we have found a significant inverse relationship between severity of mood disturbance and serum irisin levels among COPD patients. The fact that this correlation was considerably more influential among patients with BDNF levels below the sample median further supports the possibility that, in COPD, irisin links deterioration of mood to the central effects of BDNF exerted in areas closely associated with reward-related processes involved in the evolution of depression. Furthermore, our findings have a possible practical implication as the efficacy of disease management 
programs has been shown to depend greatly on the patients' ability to utilize personal resources like motivation to alter behavior and willingness to set new goals. ${ }^{61}$ Nonadherence to standard care is very frequent among COPD patients reaching $\sim 70 \%{ }^{3}$ Considering these aspects, a further consequence of altered irisin-BDNF axis (and downstream processes including mesocortico-limbic dysfunction) may be the impairment of reward-related motivation, preventing change of behavior needed for COPD management and causing lack of efficacy of disease management programs. Future interventional studies investigating the potential beneficial effect of endurance training tailored to the needs of COPD patients with respect to change of irisin-BDNF levels as well as mood and motivation are needed to further support this notion.

\section{Acknowledgments}

The authors acknowledge the contribution of Magdolna Emma Szilasi, Angela Mikaczo, and Andrea Fodor to the present investigation. This study was supported by the Scientific Research Grant of the Hungarian Foundation for Pulmonology (awarded in 2015), the National Research, Development and Innovation Office (GINOP-2.3.2-15-2016-00062 and AGR-PIAC-13-1-2013-0008), and the Hungarian Brain Research Program (KTIA_13_NAP-A-V/2).

\section{Disclosure}

The authors report no conflicts of interest in this work.

\section{References}

1. Mathers CD, Loncar D. Projections of global mortality and burden of disease from 2002 to 2030. PLoS Med. 2006;3(11):e442.

2. Uchmanowicz I, Jankowska-Polanska B, Motowidlo U, Uchmanowicz B, Chabowski M. Assessment of illness acceptance by patients with COPD and the prevalence of depression and anxiety in COPD. Int $J$ Chron Obstruct Pulmon Dis. 2016;11:963-970.

3. Ding B, DiBonaventura M, Karlsson N, Bergström G, Holmgren U. A cross-sectional assessment of the burden of COPD symptoms in the US and Europe using the National Health and Wellness Survey. Int $J$ Chron Obstruct Pulmon Dis. 2017;12:529-539.

4. Hanania NA, Müllerova H, Locantore NW, et al; Evaluation of COPD Longitudinally to Identify Predictive Surrogate Endpoints (ECLIPSE) study investigators. Determinants of depression in the ECLIPSE chronic obstructive pulmonary disease cohort. Am J Respir Crit Care Med. 2011;183(5):604-611.

5. Mikkelsen RL, Middelboe T, Pisinger C, Stage KB. Anxiety and depression in patients with chronic obstructive pulmonary disease (COPD). A review. Nord J Psychiatry. 2004;58(1):65-70.

6. Ng T, Niti M, Tan W, Cao Z, Ong K, Eng P. Depressive symptoms and chronic obstructive pulmonary disease: effect on mortality, hospital readmission, symptom burden, functional status, and quality of life. Arch Intern Med. 2007;167(1):60-67.

7. Ouellette DR LK. Recognition, diagnosis, and treatment of cognitive and psychiatric disorders in patients with COPD. Int J Chron Obstruct Pulmon Dis. 2017;12:639-650.
8. Hynninen MJ. Factors affecting health status in COPD patients with co-morbid anxiety or depression. Int J Chron Obstruct Pulmon Dis. 2007;2(3):323-328.

9. Boström P, Wu J, Jedrychowski MP, et al. A PGC1- $\alpha$-dependent myokine that drives brown-fat-like development of white fat and thermogenesis. Nature. 2012;481(7382):463-468.

10. Handschin C, Spiegelman BM. The role of exercise and PGC1 $\alpha$ in inflammation and chronic disease. Nature. 2008;454(7203):463-469.

11. Lecker SH, Zavin A, Cao P, et al. Expression of the irisin precursor FNDC5 in skeletal muscle correlates with aerobic exercise performance in patients with heart failure. Circ Heart Fail. 2012;5(6):812-818.

12. Wrann CD, White JP, Salogiannnis J, et al. Exercise induces hippocampal BDNF through a PGC-1a/FNDC5 pathway. Cell Metab. 2013;18(5):649-659.

13. Steiner JL, Murphy EA, McClellan JL, Carmichael MD, Davis JM. Exercise training increases mitochondrial biogenesis in the brain. J Appl Physiol (1985). 2011;111(4):1066-1071.

14. Zsuga J, Biro K, Papp C, Tajti G, Gesztelyi R. The "proactive" model of learning: Integrative framework for model-free and model-based reinforcement learning utilizing the associative learning-based proactive brain concept. Behav Neurosci. 2016;130(1):6-18.

15. Zsuga J, Biro K, Tajti G, et al. 'Proactive' use of cue-context congruence for building reinforcement learning's reward function. BMC Neurosci. 2016;17(1):70.

16. Kristóf E, Doan-Xuan Q, Bai P, Bacso Z, Fésüs L. Laser-scanning cytometry can quantify human adipocyte browning and proves effectiveness of irisin. Sci Rep. 2015;5:12540.

17. Phillips C, Baktir MA, Srivatsan M, Salehi A. Neuroprotective effects of physical activity on the brain: a closer look at trophic factor signaling. Front Cell Neurosci. 2014;8:170.

18. Zsuga J, Tajti G, Papp C, Juhasz B, Gesztelyi R. FNDC5/irisin, a molecular target for boosting reward-related learning and motivation. Med Hypotheses. 2016;90:23-28.

19. Yan QS, Feng MJ, Yan SE. Different expression of brain-derived neurotrophic factor in the nucleus accumbens of alcohol-preferring $(\mathrm{P})$ and-nonpreferring (NP) rats. Brain Res. 2005;1035(2):215-218.

20. Jeanblanc J, He DY, McGough NN, et al. The dopamine D3 receptor is part of a homeostatic pathway regulating ethanol consumption. J Neurosci. 2006;26(5):1457-1464.

21. Guillin O, Griffon N, Bezard E, et al. Brain-derived neurotrophic factor controls dopamine D3 receptor expression: therapeutic implications in Parkinson's disease. Eur J Pharmacol. 2003;480(1-3):89-95.

22. Maia TV. Reinforcement learning, conditioning, and the brain: Successes and challenges. Cogn Affect Behav Neurosci. 2009;9(4):343-364.

23. Pulcu E, Trotter PD, Thomas EJ, et al. Temporal discounting in major depressive disorder. Psychol Med. 2014;44(9):1825-1834.

24. Huys QJ, Pizzagalli DA, Bogdan R, Dayan P. Mapping anhedonia onto reinforcement learning: a behavioural meta-analysis. Biol Mood Anxiety Disord. 2013;3(1):12.

25. Nestler EJ, Carlezon WA. The mesolimbic dopamine reward circuit in depression. Biol Psychiatry. 2006;59(12):1151-1159.

26. Von Elm E, Altman DG, Egger M, Pocock SJ, Gøtzsche PC, Vandenbroucke JP; STROBE Initiative. The Strengthening the Reporting of Observational Studies in Epidemiology (STROBE) Statement: guidelines for reporting observational studies. Int J Surg. 2014;12(4):1495-1499.

27. Tajti G, Gesztelyi R, Pak K, et al. Positive correlation of airway resistance and serum asymmetric dimethylarginine level in COPD patients with systemic markers of low-grade inflammation. Int J Chron Obstruct Pulmon Dis. 2017;12:873-884.

28. Kollégium TS. Az Egészségügyi Minisztérium szakmai irányelve a krónikus obstruktiv légúti betegség (chronic obstructive pulmonary disease - COPD) diagnosztikájáról és kezeléséről (1. módosított változat) [Clinical practice guidelines of the Ministry of Health on diagnosis and management of chronic obstructive pulmonary disease (COPD) (first modified version)]. Magyar Közlöny. 2009;21:3661-3692. Hungarian. 
29. Rabe KF, Hurd SS, Agustí AG, et al. Global strategy for the diagnosis, management, and prevention of chronic obstructive pulmonary disease: GOLD executive summary. Am J Respir Crit Care Med. 2007; 176(6):532-555.

30. Celli BR, MacNee W; ATS/ERS Task Force. Standards for the diagnosis and treatment of patients with COPD: a summary of the ATS/ ERS position paper. Eur Respir J. 2004;23(6):932-946.

31. Swanney MP, Ruppel G, Enright PL, et al. Using the lower limit of normal for the $\mathrm{FEV}_{1} / \mathrm{FVC}$ ratio reduces the misclassification of airway obstruction. Thorax. 2008;63(12):1046-1051.

32. Nathell L, Nathell M, Malmberg P, Larsson K. COPD diagnosis related to different guidelines and spirometry techniques. Respir Res. 2007;8:89.

33. Meguro M, Barley EA, Spencer S, Jones PW. Development and validation of an improved, COPD-specific version of the St. George Respiratory Questionnaire. Chest. 2007;132(2):456-463.

34. Miller MR, Hankinson J, Brusasco V, et al; ATS/ERS Task Force Standardisation of spirometry. Eur Respir J. 2005;26(2):319-338.

35. Wanger J, Clausen JL, Coates A, et al. Standardisation of the measurement of lung volumes. Eur Respir J. 2005;26(3):511-522.

36. Zsuga J, Török J, Magyar MT, et al. Dimethylarginines at the crossroad of insulin resistance and atherosclerosis. Metabolism. 2007 56(3):394-399.

37. Jones PW, Quirk F, Baveystock C. The St George's respiratory questionnaire. Respir Med. 1991;85(Suppl B):25-31; discussion 33-37.

38. Jones PW. St. George's respiratory questionnaire: MCID. COPD. 2005;2(1):75-79.

39. Ferrer M, Villasante $\mathrm{C}$, Alonso J, et al. Interpretation of quality of life scores from the St George's Respiratory Questionnaire. Eur Respir J. 2002;19(3):405-413.

40. Lambert AA, Putcha N, Drummond MB, et al; COPD Gene Investigators. Obesity is associated with increased morbidity in moderate to severe COPD. Chest. 2017;151(1):68-77.

41. Ho SC, Hsu MF, Kuo HP, et al. The relationship between anthropometric indicators and walking distance in patients with chronic obstructive pulmonary disease. Int J Chron Obstruct Pulmon Dis. 2015; 10:1857-1862.

42. Tanni SE, Zamuner AT, Coelho LS, Vale SA, Godoy I, Paiva SA. Are metabolic syndrome and its components associated with 5-year mortality in chronic obstructive pulmonary disease patients? Metab Syndr Relat Disord. 2015;13(1):52-54.

43. Catalfo G, Crea L, Lo Castro T, et al. Depression, body mass index, and chronic obstructive pulmonary disease - a holistic approach. Int $J$ Chron Obstruct Pulmon Dis. 2016;11:239-249.

44. Vogelmeier CF, Criner GJ, Martinez FJ, et al. Global strategy for the diagnosis, management and prevention of chronic obstructive lung disease 2017 report: GOLD Executive Summary. Am J Respir Crit Care Med. 2017;195(5):557-582.

45. Diaz AA, Petersen H, Meek P, Sood A, Celli B, Tesfaigzi Y. Differences in health-related quality of life between new Mexican hispanic and non-hispanic white smokers. Chest. 2016;150(4):869-876.
46. Welling JB, Hartman JE, Ten Hacken NH, Klooster K, Slebos DJ. The minimal important difference for the St George's Respiratory Questionnaire in patients with severe COPD. Eur Respir J. 2015; 46(6):1598-1604

47. Jones PW, Anderson JA, Calverley PM, et al; TORCH investigators. Health status in the TORCH study of COPD: treatment efficacy and other determinants of change. Respir Res. 2011;12:71.

48. Duman RS, Heninger GR, Nestler EJ. A molecular and cellular theory of depression. Arch Gen Psychiatry. 1997;54(7):597-606.

49. Jeon SW, Kim YK. Molecular neurobiology and promising new treatment in depression. Int J Mol Sci. 2016;17(3):381.

50. Ihara K, Yoshida H, Jones PB, et al. Serum BDNF levels before and after the development of mood disorders: a case-control study in a population cohort. Transl Psychiatry. 2016;6:e782.

51. Brunoni AR, Lopes M, Fregni F. A systematic review and meta-analysis of clinical studies on major depression and BDNF levels: implications for the role of neuroplasticity in depression. Int $J$ Neuropsychopharmacol. 2008;11(8):1169-1180.

52. Kheirouri S, Noorazar SG, Alizadeh M, Dana-Alamdari L. Elevated brain-derived neurotrophic factor correlates negatively with severity and duration of major depressive episodes. Cogn Behav Neurol. 2016;29(1):24-31

53. Groves JO. Is it time to reassess the BDNF hypothesis of depression? Mol Psychiatry. 2007;12(12):1079-1088.

54. Ijiri N, Kanazawa H, Asai K, Watanabe T, Hirata K. Irisin, a newly discovered myokine, is a novel biomarker associated with physical activity in patients with chronic obstructive pulmonary disease. Respirology. 2015;20(4):612-617.

55. Kureya Y, Kanazawa H, Ijiri N, et al. Down-regulation of soluble $\alpha-K$ lotho is associated with reduction in serum irisin levels in chronic obstructive pulmonary disease. Lung. 2016;194(3):345-351.

56. Stoll P, Wuertemberger U, Bratke K, Zingler C, Virchow JC, Lommatzsch M. Stage-dependent association of BDNF and TGF- $\beta 1$ with lung function in stable COPD. Respir Res. 2012;13:116.

57. Jacoby AS, Munkholm K, Vinberg M, Pedersen BK, Kessing LV. Cytokines, brain-derived neurotrophic factor and C-reactive protein in bipolar I disorder - Results from a prospective study. J Affect Disord. 2016;197:167-174.

58. Failla MD, Conley YP, Wagner AK. Brain-derived neurotrophic factor (BDNF) in traumatic brain injury-related mortality: interrelationships between genetics and acute systemic and central nervous system BDNF profiles. Neurorehabil Neural Repair. 2016;30(1):83-93.

59. Chuang ML, Lin IF, Lee CY. Clinical assessment tests in evaluating patients with chronic obstructive pulmonary disease: a cross-sectional study. Medicine (Baltimore). 2016;95(47):e5471.

60. Jones PW, Quirk FH, Baveystock CM, Littlejohns P. A self-complete measure of health status for chronic airflow limitation. Am Rev Respir Dis. 1992;145(6):1321-1327.

61. Effing TW, Lenferink A, Buckman J, et al. Development of a selftreatment approach for patients with COPD and comorbidities: an ongoing learning process. J Thorac Dis. 2014;6(11):1597-1605.
International Journal of COPD

\section{Publish your work in this journal}

The International Journal of COPD is an international, peer-reviewed journal of therapeutics and pharmacology focusing on concise rapid reporting of clinical studies and reviews in COPD. Special focus is given to the pathophysiological processes underlying the disease, intervention programs, patient focused education, and self management protocols.

\section{Dovepress}

This journal is indexed on PubMed Central, MedLine and CAS. The manuscript management system is completely online and includes a very quick and fair peer-review system, which is all easy to use. Visi http://www.dovepress.com/testimonials.php to read real quotes from published authors. 